\title{
Mechanism of Sinus Bradycardia in Carriers of the A414G Mutation in the HCN4 Gene
}

\author{
Arie O. Verkerk ${ }^{1,2}$ and Ronald Wilders ${ }^{1}$ \\ ${ }^{1}$ Department of Medical Biology, Academic Medical Center, University of Amsterdam, \\ Amsterdam, The Netherlands \\ ${ }^{2}$ Department of Experimental Cardiology, Academic Medical Center, University of Amsterdam, \\ Amsterdam, The Netherlands
}

\begin{abstract}
Heterozygous carriers of the $A 414 G$ mutation in the HCN4 gene, which encodes the HCN4 protein, show moderate to severe sinus bradycardia. Tetramers of HCN4 subunits constitute the ion channels that conduct the cardiac hyperpolarization-activated 'funny current' $\left(I_{f}\right)$, which plays an important modulating role in the pacemaker activity of sinus node cells.

We assessed the mechanism by which the A414G mutation in HCN4 causes sinus bradycardia. We carried out voltage clamp experiments on HCN4 channels expressed in Chinese hamster ovary (CHO) cells and incorporated the experimentally observed mutationinduced changes in $I_{f}$ into the Fabbri-Severi model of a single human sinus node cell.

In the Fabbri-Severi model, the experimentally observed effects on $I_{f}$ increased the cycle length from 813 to $1004 \mathrm{~ms}$, corresponding with a 19\% decrease in beating rate from 74 to 60 beats/min. These mutation effects became more prominent at $10 \mathrm{nM} \mathrm{ACh}$ (vagal tone) and in the presence of a hyperpolarizing atrial load.

We conclude that the experimentally identified mutation-induced changes in $I_{f}$ can explain the clinically observed sinus bradycardia in carriers of the $A 414 G$ mutation in the HCN4 gene.
\end{abstract}

\section{Introduction}

The hyperpolarization-activated 'funny current' $\left(I_{\mathrm{f}}\right)$, also known as 'pacemaker current', is a key player in sinoatrial node (SAN) pacemaker activity. This (mainly) inward current of mixed ionic nature is a determinant of the spontaneous depolarization that underlies SAN pacemaker activity and thus a modulator of pacing rate $[1,2]$. The $I_{\mathrm{f}}$ ion channel in the cell membrane is constituted by four hyperpolarization-activated, cyclic-nucleotidegated (HCN) subunits. The HCN4 protein, which is encoded by the $\mathrm{HCN} 4$ gene, is the dominant $\mathrm{HCN}$ isoform in rabbit and human SAN [3-6].

Since 2003, several loss-of-function mutations in the HCN4 gene have been associated with human sinus bradycardia [7,8]. We reviewed these mutations in 2014 [9] and, more recently, in 2015 [10]. Around that time, Milano et al. [11] and Schweizer et al. [12] were the first to report on an intriguing association between loss-offunction mutations in HCN4 and left ventricular noncompaction (LVNC). Milano et al. [11] observed such non-compaction for the G482R, Y481H, and A414G missense mutations and Schweizer et al. [12] for the G482R and P883R missense mutations, and the 695X truncation mutation [12]. Each of these loss-of-function mutations is also associated with sinus bradycardia.

In the present study, we assessed the mechanism by which the aforementioned A414G mutation in HCN4 causes sinus bradycardia. To this end, we first carried out voltage clamp experiments on wild-type and heterozygous mutant HCN4 channels expressed in Chinese hamster ovary (CHO) cells. Next, we incorporated the experimentally identified mutation-induced changes in the kinetics of the HCN4 channels into the comprehensive mathematical model of a single human SAN pacemaker cell that was developed by Fabbri et al. [13] (Fabbri-Severi model). This model allows different levels of autonomic tone through the simulated administration of acetylcholine (ACh; vagal tone) or isoprenaline (Iso; $\beta$-adrenergic tone). Computer simulations were carried out without autonomic tone, in presence of $10 \mathrm{nM} \mathrm{ACh}$ to test vagal effects, and in the absence or presence of an additional outward current with a conductance of $0.4-0.8 \mathrm{pS} / \mathrm{pF}$ and a reversal potential of $-80 \mathrm{mV}$ to test the effects of sinus node-atrial interactions.

\section{Methods}

\subsection{Patch clamp experiments}

The A414G mutation was introduced in wild-type (WT) hHCN4 complementary DNA (cDNA) as described 
previously [11]. Chinese hamster ovary (CHO) cells were transiently transfected with lipofectamine using either $2 \mu \mathrm{g}$ WT cDNA, or, to recapitulate a heterozygous state, $1 \mu \mathrm{g}$ of WT and $1 \mu \mathrm{g}$ of mutant HCN4 construct. HCN4 currents were recorded at $36 \pm 0.2^{\circ} \mathrm{C}$ two days after transfection using the amphotericin-perforated patch-clamp technique. The amplitude, kinetics and reversal potential of the HCN4 current were determined by voltage clamp protocols as described previously $[11,14]$.

The $I_{\mathrm{f}}$ activation curves were fitted with a Boltzmann equation to determine the half-maximum activation voltage $\left(V_{1 / 2}\right)$ and slope factor $(k)$. The time constants of $I_{\mathrm{f}}$ (de)activation were obtained by fitting the time course of $I_{\mathrm{f}}$ (de)activation with a monoexponential equation, ignoring the variable initial delay in $I_{\mathrm{f}}(\mathrm{de})$ activation.

\subsection{Computer simulations}

The heterozygous A414G mutation in HCN4 was implemented in the CellML code [15] of the Fabbri et al. model [13] by shifting the voltage dependence of the steady-state activation curve and (de)activation time constant of $I_{\mathrm{f}}$ by and -25.7 and $-11.3 \mathrm{mV}$, respectively, based on the data from our patch clamp experiments.

The default Fabbri et al. model [13] has a beating rate of 74 beats $/ \mathrm{min}$. This rate was lowered to 58 beats $/ \mathrm{min}$ (vagal tone) through the simulated administration of $10 \mathrm{nM}$
ACh. The major effects of the administration of ACh are the activation of the ACh-activated potassium current $I_{\mathrm{K}, \mathrm{ACh}}$, which is zero in the default model, and the inhibition of $I_{\mathrm{f}}$ through a negative shift in its voltage dependence [13]. The effects of sinus node-atrial interactions were tested through the addition of an ohmic outward current with a conductance of $0.4-0.8 \mathrm{pS} / \mathrm{pF}$ and a reversal potential of $-80 \mathrm{mV}$.

The CellML code was edited and run in the Cellular Open Resource (COR) environment [16], version 0.9 .31 .1409 . All simulations were run for a sufficiently long time to reach steady-state behaviour.

\section{Results}

\subsection{Patch clamp experiments}

We carried voltage clamp experiments to assess the effects of the heterozygous A414G mutation in $\mathrm{HCN} 4$ on the functional properties of $I_{\mathrm{f}}$. These experiments revealed a mutation-induced $-25.7 \mathrm{mV}$ shift in $V_{1 / 2}$ of the $I_{\mathrm{f}}$ steadystate activation curve without a significant change in its slope factor (data not shown). This prominent shift was accompanied by a significant $-11.3 \mathrm{mV}$ shift in the voltage dependence of the time constant of $I_{\mathrm{f}}(\mathrm{de})$ activation. The mutation did not affect the fully-activated conductance of $I_{\mathrm{f}}$ or its reversal potential.
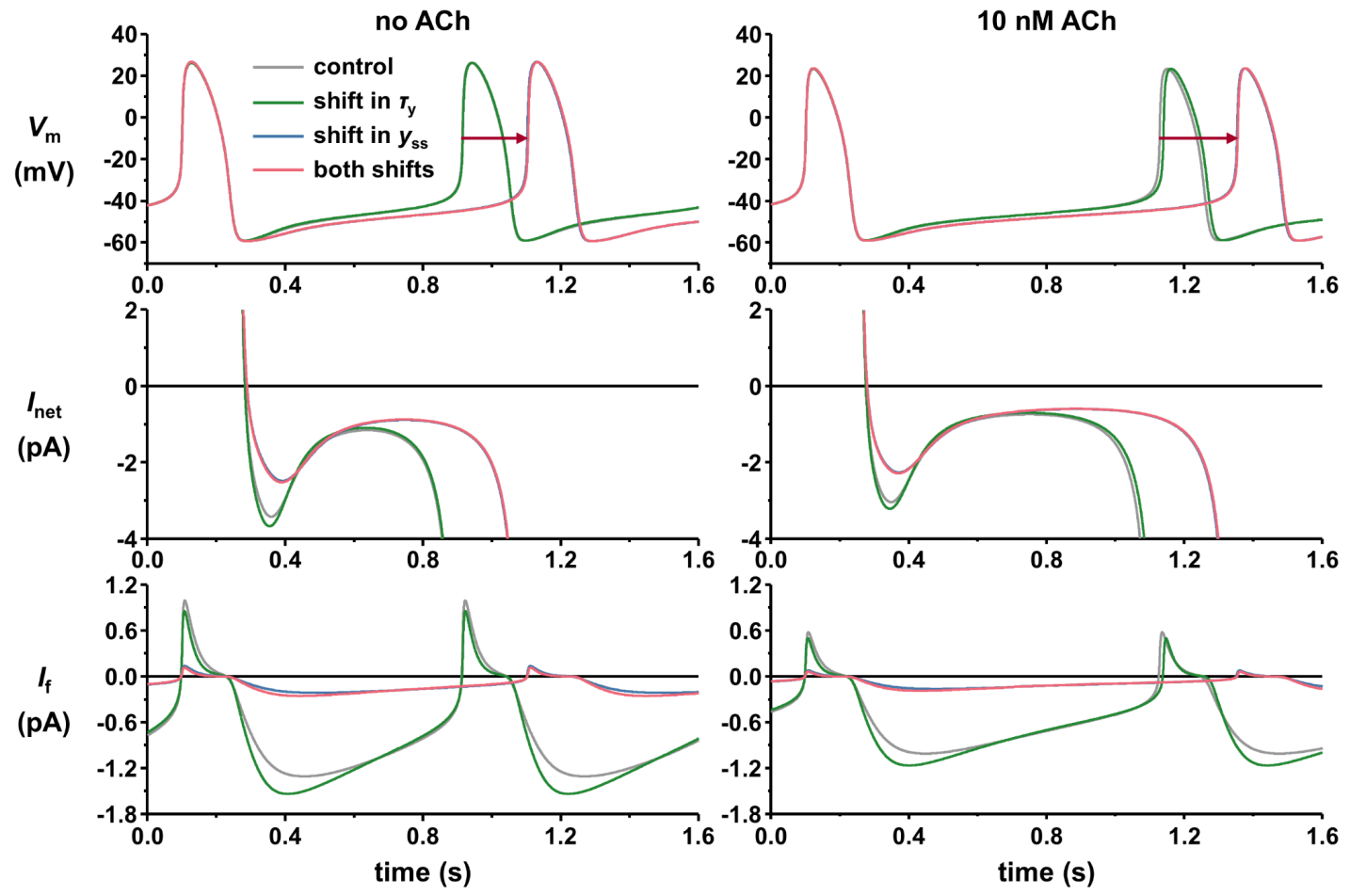

Figure 1. Pacemaker activity in the Fabbri-Severi model of a single human SAN pacemaker cell. Effects of the HCN4A414G mutation-induced -25.7 and $-11.3 \mathrm{mV}$ shifts in the steady-state activation $\mathrm{y}_{\mathrm{ss}}$ and (de)activation time constant $\tau_{\mathrm{y}}$, respectively, of the hyperpolarization-activated 'funny current' $\left(I_{\mathrm{f}}\right)$ on the membrane potential $\left(V_{\mathrm{m}}\right.$, top), net membrane current ( $I_{\text {net }}$, middle), and $I_{\mathrm{f}}($ bottom) under control conditions (no ACh, left) and in the presence of $10 \mathrm{nM} \mathrm{ACh}$ (right). 

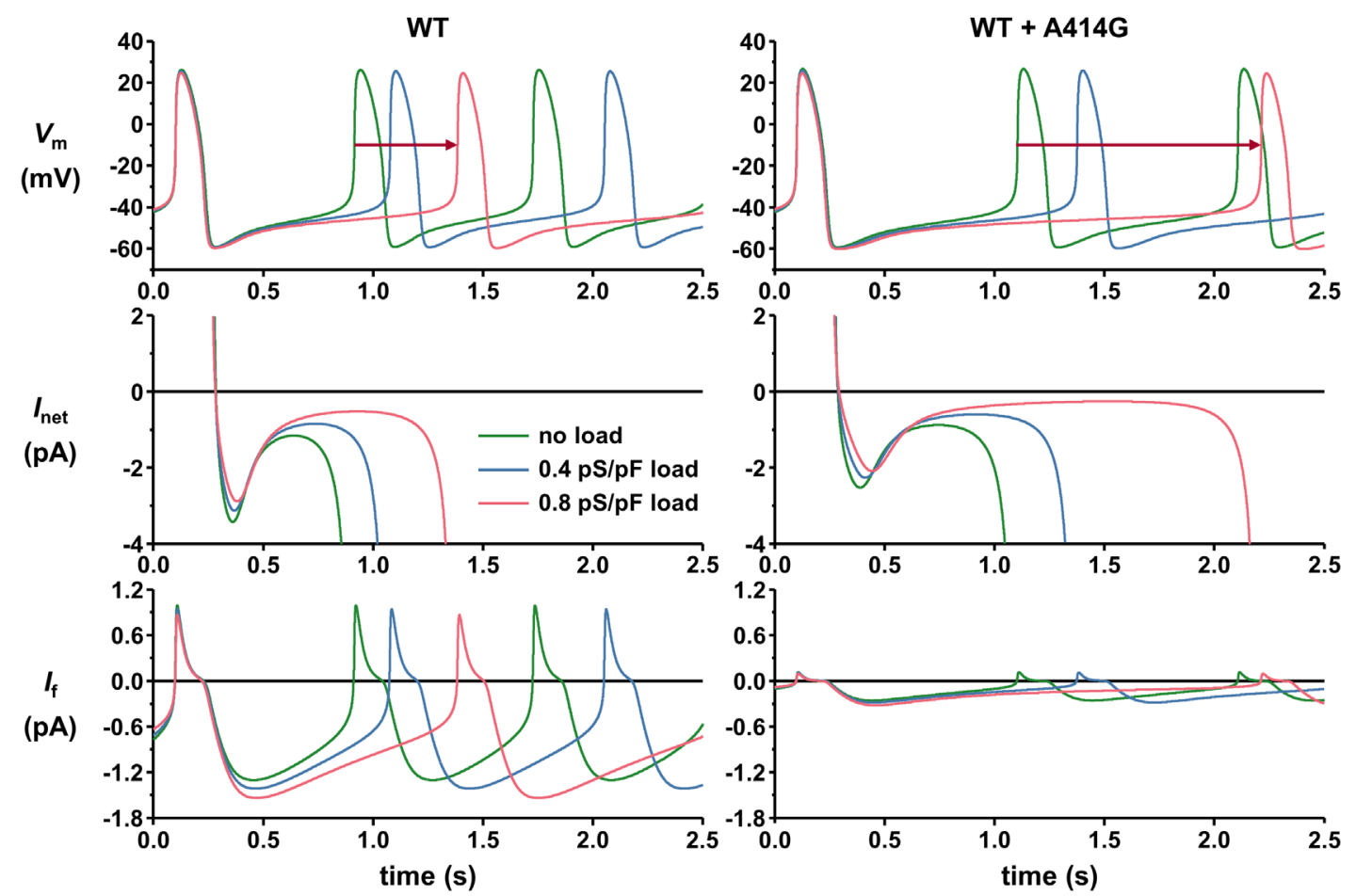

Figure 2. Pacemaker activity in the Fabbri-Severi model of a single human SAN pacemaker cell. Effects of atrial load (i.e., an outward current with a conductance of $0.4-0.8 \mathrm{pS} / \mathrm{pF}$ and a reversal potential of $-80 \mathrm{mV}$ ) on the membrane potential ( $V_{\mathrm{m}}$, top), the net membrane current $\left(I_{\text {net, }}\right.$, middle), and the hyperpolarization-activated 'funny current' $\left(I_{\mathrm{f}}\right.$, bottom) under wild-type conditions (WT, left) and in the presence of the heterozygous HCN4-A414G mutation (WT + A414G, right).

\subsection{Computer simulations}

Fig. 1 shows the effects of the $-25.7 \mathrm{mV}$ shift in the steady-state activation of $I_{\mathrm{f}}\left(\mathrm{y}_{\mathrm{ss}}\right)$ as well as the $-11.3 \mathrm{mV}$ shift in its (de)activation time constant $\left(\tau_{\mathrm{y}}\right)$ on pacemaker activity. The horizontal arrows indicate the mutationinduced increase in cycle length under control conditions (left) and in the presence of $10 \mathrm{nM} \mathrm{ACh}$ (right). This increase amounts to 191 and $227 \mathrm{~ms}$, respectively, and is almost completely attributable to the $-25.7 \mathrm{mV}$ shift in $\mathrm{y}_{\mathrm{ss}}$. The beating rate decreases by $19 \%$ (from 74 to 60 beats/min) under control conditions and by $18 \%$ (from 58 to 48 beats $/ \mathrm{min}$ ) in the presence of $10 \mathrm{nM} \mathrm{ACh}$.

Fig. 2 shows the effects of atrial load on pacemaker activity under wild-type conditions (left) and in the presence of the heterozygous HCN4-A414G mutation (right). In the latter case, the model cell is more sensitive to atrial load, with an increase in cycle length up to $1110 \mathrm{~ms}(+110 \%)$ in case of $0.8 \mathrm{pS} / \mathrm{pF}$ load as compared to $470 \mathrm{~ms}(+58 \%)$ under control conditions (horizontal arrows).

The combined effects of atrial load and vagal tone (10 $\mathrm{nM} \mathrm{ACh}$ ) on pacemaker activity are shown in Fig. 3. Under wild-type conditions, an atrial load of $0.4 \mathrm{pS} / \mathrm{pF}$ results in a $39 \%$ increase in cycle length from 1027 to $1428 \mathrm{~ms}$, whereas an atrial load of $0.6 \mathrm{pS} / \mathrm{pF}$ results in a $94 \%$ increase in cycle length to $1988 \mathrm{~ms}$. The effects of atrial load are much more pronounced in the presence of the heterozygous HCN4-A414G mutation. An atrial load of $0.4 \mathrm{pS} / \mathrm{pF}$ results in a $68 \%$ increase in cycle length from 1276 to $2146 \mathrm{~ms}$, whereas an atrial load of $0.6 \mathrm{pS} / \mathrm{pF}$ results in a complete loss of pacemaker activity. The beating rate at $0.4 \mathrm{pS} / \mathrm{pF}$ amounts to 42 beats $/$ min under wild-type conditions and 28 beats/min in the presence of the heterozygous HCN4-A414G mutation

\section{Conclusion}

We conclude that the experimentally observed changes in the kinetics of $I_{\mathrm{f}}$ can explain the sinus bradycardia that has been identified in carriers of the A414G loss-offunction mutation in $\mathrm{HCN} 4$.

\section{References}

[1] Baruscotti M, Barbuti A, Bucchi A. The cardiac pacemaker current. J Mol Cell Cardiol 2010;48:55-64.

[2] DiFrancesco D. The role of the funny current in pacemaker activity. Circ Res 2010;106:434-46.

[3] Shi W, Wymore R, Yu H, Wu J, Wymore RT, Pan Z, Robinson RB, Dixon JE, McKinnon D, Cohen IS. Distribution and prevalence of hyperpolarization-activated cation channel (HCN) mRNA expression in cardiac tissues. 

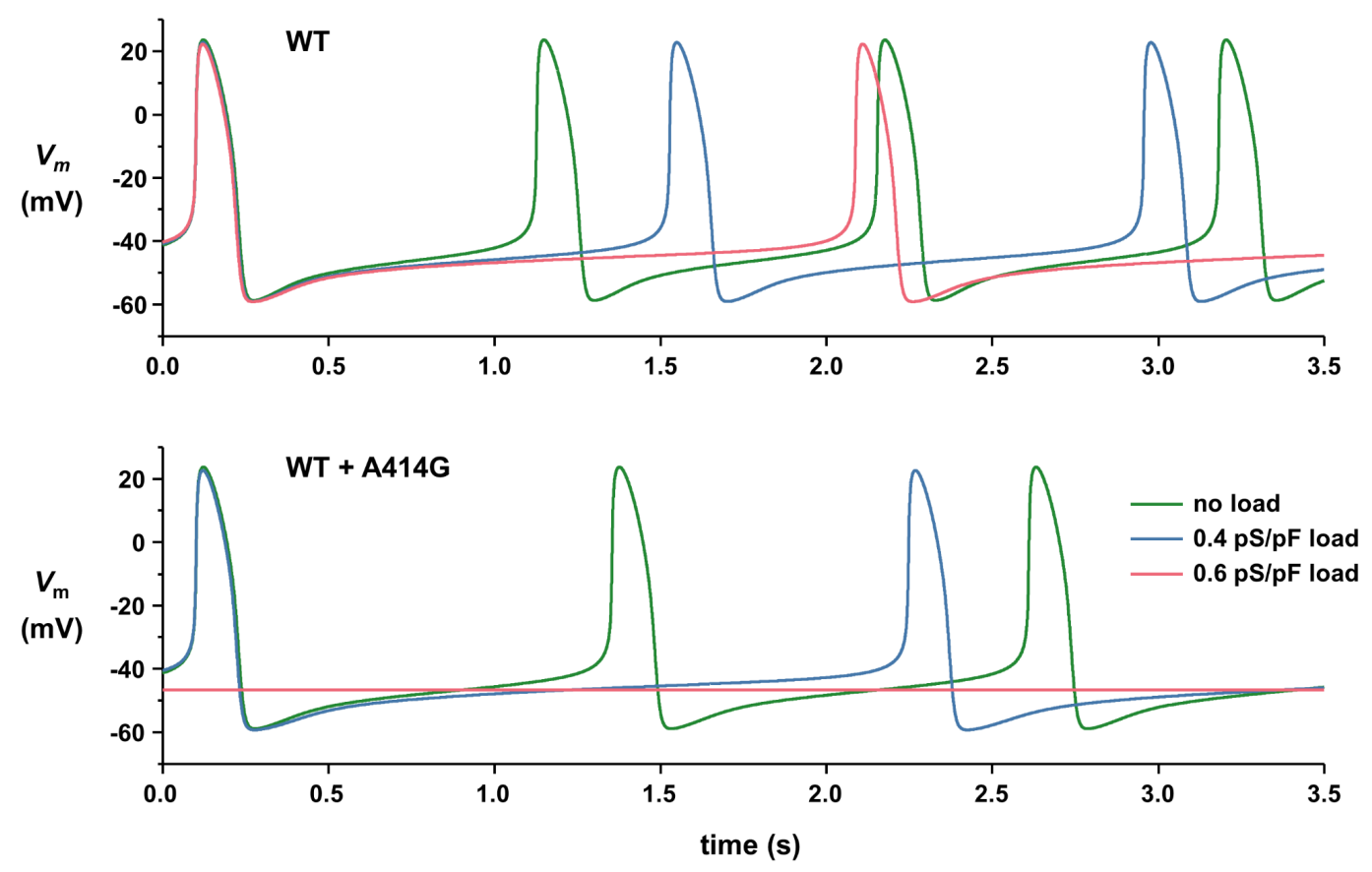

Figure 3. Pacemaker activity in the Fabbri-Severi model of a single human SAN pacemaker cell. Effects of atrial load in presence of vagal tone $(10 \mathrm{nM} \mathrm{ACh})$ on the membrane potential $\left(V_{\mathrm{m}}\right)$ under control conditions (WT, top) and in the presence of the heterozygous HCN4-A414G mutation (WT + A414G, bottom).

Circ Res 1999;85:e1-6.

[4] Tellez JO, Dobrzynski H, Greener ID, Graham GM, Laing E, Honjo H, Hubbard SJ, Boyett MR, Billeter R. Differential expression of ion channel transcripts in atrial muscle and sinoatrial node in rabbit. Circ Res 2006;99:1384-93.

[5] Brioschi C, Micheloni S, Tellez JO, Pisoni G, Longhi R, Moroni P, Billeter R, Barbuti A, Dobrzynski H, Boyett MR, DiFrancesco D, Baruscotti M. Distribution of the pacemaker HCN4 channel mRNA and protein in the rabbit sinoatrial node. J Mol Cell Cardiol 2009;47:221-7.

[6] Chandler NJ, Greener ID, Tellez JO, Inada S, Musa H, Molenaar P, DiFrancesco D, Baruscotti M, Longhi R, Anderson RH, Billeter R, Sharma V, Sigg DC, Boyett MR, Dobrzynski H. Molecular architecture of the human sinus node: insights into the function of the cardiac pacemaker. Circulation 2009;119:1562-75.

[7] Baruscotti M, Bottelli G, Milanesi R, DiFrancesco JC, DiFrancesco D. HCN-related channelopathies. Pflügers Arch 2010;460:405-15.

[8] DiFrancesco D. Funny channel gene mutations associated with arrhythmias. J Physiol 2013;591:4117-24.

[9] Verkerk AO, Wilders R. Pacemaker activity of the human sinoatrial node: effects of HCN4 mutations on the hyperpolarization-activated current. Europace 2014;16: 384-95.

[10] Verkerk AO, Wilders R. Pacemaker activity of the human sinoatrial node: an update on the effects of mutations in HCN4 on the hyperpolarization-activated current. Int J Mol Sci 2015;16:3071-94.

[11] Milano A, Vermeer AMC, Lodder EM, Barc J, Verkerk AO, Postma AV, Van der Bilt IAC, Baars MJH, Van Haelst PL, Caliskan K, Hoedemaekers YM, Le Scouarnec S, Redon R, Pinto YM, Christiaans I, Wilde AAM, Bezzina CR. HCN4 mutations in multiple families with bradycardia and left ventricular noncompaction cardiomyopathy. J Am Coll Cardiol 2014;64:745-56.

[12] Schweizer PA, Schröter J, Greiner S, Haas J, Yampolsky P, Mereles D, Buss SJ, Seyler C, Bruehl C, Draguhn A, Koenen M, Meder B, Katus HA, Thomas D. The symptom complex of familial sinus node dysfunction and myocardial noncompaction is associated with mutations in the HCN4 channel. J Am Coll Cardiol 2014;64:757-67.

[13] Fabbri A, Fantini M, Wilders R, Severi S. Computational analysis of the human sinus node action potential: model development and effects of mutations. J Physiol 2017; 595:2365-96.

[14] Verkerk AO, Den Ruijter HM, Bourier J, Boukens BJ, Brouwer IA, Wilders R, Coronel R. Dietary fish oil reduces pacemaker current and heart rate in rabbit. Heart Rhythm 2009;6:1485-92.

[15] Cuellar AA, Lloyd CM, Nielsen PF, Bullivant DP, Nickerson DP, Hunter PJ. An overview of CellML 1.1, a biological model description language. Simulation 2003; 79:740-7.

[16] Garny A, Kohl P, Noble D. Cellular open resource (COR): a public CellML based environment for modelling biological function. Int J Bifurcat Chaos 2003;13:3579-90.

Address for correspondence:

Ronald Wilders, $\mathrm{PhD}$

Academic Medical Center, University of Amsterdam, Department of Medical Biology

Meibergdreef 15, 1105 AZ Amsterdam, The Netherlands

Phone: +31-20-5665229

E-mail: r.wilders@amc.uva.nl 